\title{
Effects on Uric Acid Metabolism of the Drugs except the Antihyperuricemics \\ Yuji Moriwaki*
}

Division of Diabetes, Endocrinology and Metabolism, Department of Internal Medicine, Hyogo College of Medicine, Mukogawa-cho 1-1, Nishinomiya, Hyogo 663-8501, Japan

\begin{abstract}
A number of drugs commonly used in clinical practice can affect the serum concentration of uric acid. Some raise serum uric acid level by an increase in uric acid production or a decrease in uric acid excretion, while others lower serum uric acid level by an increase in uric acid excretion or decrease in uric acid absorption from intestine. In addition, salicylate shows so-called "biphasic effect". At small doses it raises serum uric acid level, while at higher doses it lowers serum uric acid concentration. To understand the effects of those pharmacological agents on uric acid metabolism will help to avoid unexpected side effect of hyperuricemia and gout flare. In addition, hypouricemic property of some drugs may obviate the need for polypharmacy and improve the medication compliance.
\end{abstract}

Keywords: Pharmacological Agents; Hyperuricemia; Hypouricemia; Uric acid production; Uric acid excretion

\section{Introduction}

The normal adult male has a total body urate pool of approximately $1200 \mathrm{mg}$. Daily turnover of about 60 percent of the urate pool is achieved by balanced production and elimination of uric acid. About one-third of the human uric acid is derived from diet, while two-thirds is generated endogenously. The major site of purine synthesis is in the liver. The synthesis of uric acid occurs along two pathways, referred to as the de novo and the salvage pathways. Synthesis of the purine nucleotides begins with the formation of phosphoribosyl pyrophosphate (PRPP) by PRPP synthetase and leads to the first fully formed nucleotide, inosine 5 '-monophosphate (IMP). IMP is converted into either adenosine 5'-monophosphate (AMP) or guanosine 5'-monophosphate (GMP) through two distinct reaction pathways. Catabolism of the purine nucleotides leads ultimately to the production of uric acid (Figure 1). On the other hand, about two-thirds of daily uric acid is excreted via the kidneys, and the remainder is excreted in feces. Many transport proteins are candidate participants in urate handling, with URAT1, GLUT9 and ABCG2 being the best characterized to date (Figure 2).

Drugs are included in the factors that alter uric acid metabolism, besides genetics, renal insufficiency, hypertension, obesity, high consumption of alcohol beverages and fructose. A large number of drugs affect the serum concentration of uric acid. Some raise serum uric acid level by an increase in uric acid production or a decrease in uric acid excretion, while others lower serum uric acid level by an increase in uric acid excretion and decrease in absorption. In addition, some drugs, such as salicylate shows so-called "biphasic effect"; for example, it causes hyperuricemia in lower doses but hypouricemia in larger doses. Among hyperuricemic agents, diuretics and pyrazinamide are the most famous ones. It will help to avoid unexpected side effect of hyperuricemia and gout flare to understand the hyperuricemic effect of those agents. On the other hand, although clinical significance of hypouricemic agents other than uricosurics has not been established, agents such as losartan and/or fenofibrate may obviate the need for polypharmacy against hypertension and/or hypertriglyceridemia, which are frequently associated with gout/hyperuricemia. However, some of hypouricemic agents may induce nephrolithiasis by a significant increase in uric acid excretion. In this review, drugs that affect uric acid metabolism are summarized with regard to their pathogenesis and clinical significance [1].

\section{Drugs that Raise Serum Uric Acid Concentration}

\section{Decreased uric acid excretion}

Decreased renal excretion of uric acid is the most common cause of hyperuricemia. Many drugs have been found to alter process of uric acid excretion and induce a rise in serum uric acid concentration.

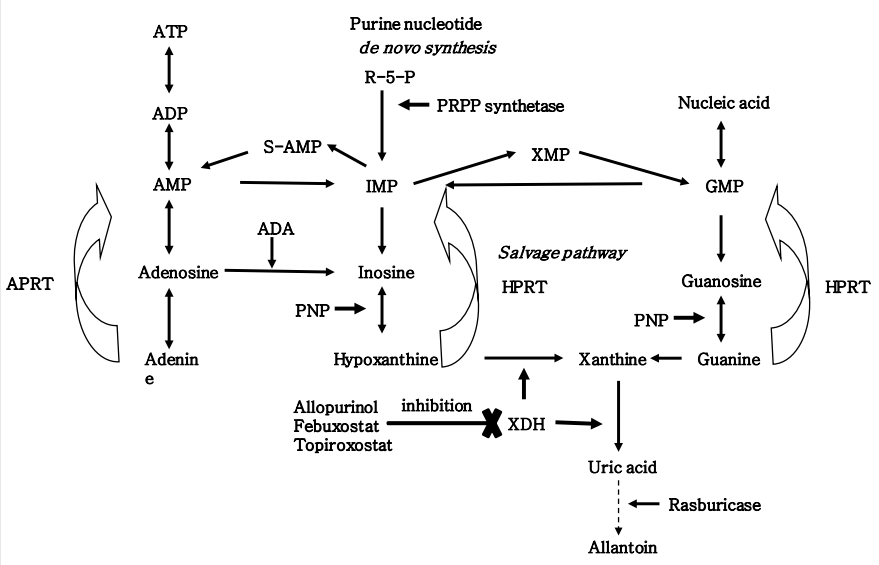

Abbreviations: ADA, adenosine deaminase; APRT, adenosine phosphoribosyl transferase; HPRT, hypoxanthine phosphoribosyl transferase; PNP, purine nucleoside phosphorylase; $\mathrm{XDH}$, xanthine dehydrogenase

Figure 1: Purine metabolic pathway in humans.

*Corresponding author: Yuji moriwaki, Division of Diabetes, Endocrinology and Metabolism, Department of Internal Medicine, Hyogo College of Medicine Mukogawa-cho 1-1, Nishinomiya, Hyogo 663-8501, Japan, Fax: +81 79845 6474; E-mail: moriwaki@hyo-med.ac.jp

Received December 01, 2013; Accepted December 30, 2013; Published January 07, 2014

Citation: Moriwaki Y (2014) Effects on Uric Acid Metabolism of the Drugs except the Antihyperuricemics. J Bioequiv Availab 6: 010-017. doi:10.4172/jbb.1000173

Copyright: (๑) 2014 Moriwaki Y. This is an open-access article distributed under the terms of the Creative Commons Attribution License, which permits unrestricted use, distribution, and reproduction in any medium, provided the original author and source are credited. 


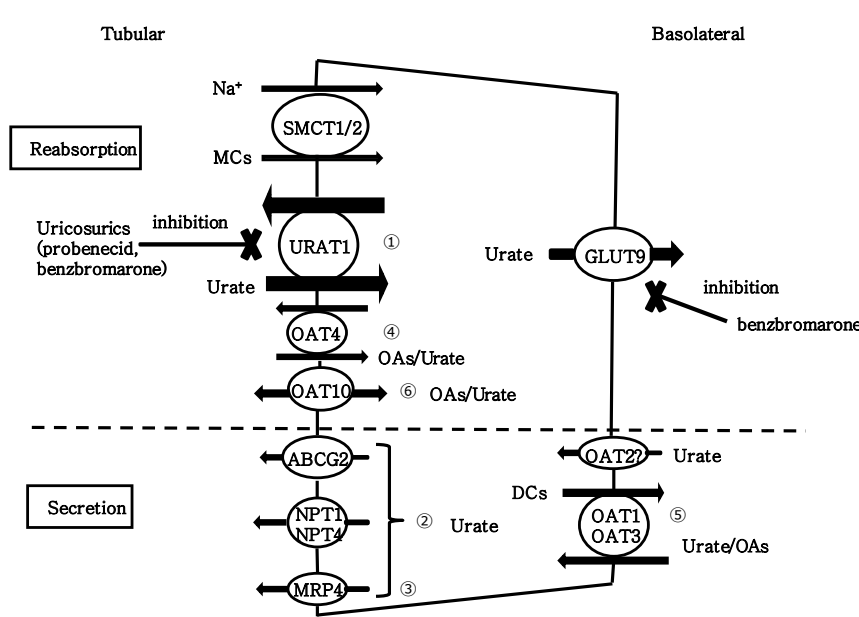

Action site of various drugs on uric acid transporters.

(1) lactate, nicotinate, pyrazinoate, high dose aspirin?, fenofibrate, losartan

(2) furosemide, bumetanide

(3) furosemide, thiazides

(4) hydrochlorothiazide, torasemide

(5) torasemide, low dose aspirin

(6) lactate, nicotinate, pyrazinoate, cyclosporine

Figure 2: Candidate transport proteins involved in urate handling in the human proximal tubule and action site of various drugs on urate transporters.

Diuretics, pyrazinamide, nicotinamide, lactate, testosterone, and low dose salicylate are the representative drugs, which raise serum uric acid levels by a decrease in urinary uric acid excretion. Among them diuretic is probably the most common form of drug-induced hyperuricemia (Table 1).

\section{Diuretics}

Hyperuricemia is a relatively common finding in patients treated with loop diuretics and thiazide-type diuretics. It has been considered that diuretics raise serum uric acid concentration by decreasing circulating plasma volume. Diuretics reduce uric acid excretion by both directly and indirectly increasing uric acid reabsorption and decreasing uric acid secretion [2-4]. Recent studies on uric acid transporters revealed that multidrug resistance-associated protein 4 (MRP4), sodium-dependent phosphate transport protein 4 (NPT4), and organic anion transporters (OATs) are involved in the diureticsinduced hyperuricemia.

Loop diuretics are widely used to treat excessive fluid accumulation and edema of the body caused by cardiac failure, chronic kidney disease (CKD), and liver cirrhosis. Furosemide (20 mg, IV) decreased renal excretion and fractional clearance of uric acid when measured 1 to 2 hours after administration. Moreover, furosemide increased the plasma concentration of uric acid at 1.5 hours after administration [5]. Whether furosemide has any effect on URAT1 (SLC22A12) remains unknown. Torasemide is the most potent of a newer of loop diuretics. Although, torasemide and its metabolites did not interact with human URAT1, competitive inhibition of the basolateral OAT for uric acid may reduce tubular secretion. Because hOAT4 can reabsorb uric acid from the urinary lumen, increased uric acid reabsorption may occur as exchange for the secretion of torasemide and its metabolites, which suggests that affinity for OAT of torasemide and its metabolites is proposed a mechanism underlying torasemide-induced hyperuricemia [6]. hNPT4, localized at the apical side of the proximal tubules, functions as uric acid transporter, with which loop diuretics, such as furosemide and bumetanide interact. Therefore, hNPT4 may play an important role in these diuretics-induced hyperuricemia [7].

Thiazides are mainly used to treat high blood pressure. Thiazides compete for the same secretory process by which uric acid is secreted into the proximal tubule, thus reducing the clearance of uric acid, and raise the levels of uric acid in the blood. hOAT4, located at the apical membrane of proximal tubule cells, is responsible for facilitation of hydrochlorothiazide-associated hyperuricemia [3]. After furosemide and hydrochlorothiazide are taken up by OAT1 and/or OAT3 into the renal tubular cells, they inhibit MRP4-mediated uric acid efflux competitively and cause retention of uric acid, thus MRP4 has an important role in their hyperuricemic mechanisms [4,8]. Increasing the dose of diuretic led to progressive hyperuricemia, thus diureticsinduced hyperuricemia seems to be dose dependent [9-11].

Potassium-sparing diuretics, spironolactone is generally considered not to affect serum uric acid level $[12,13]$. However it has been reported that spironolactone increased serum uric acid levels in the CKD patients [14], although the mechanism responsible for the increase in uric acid is unclear.

\section{Pyrazinamide and nicotinamide}

Pyrazinamide is an anti-tubeculous agent, and it increases serum uric acid level through decrease in uric acid excretion [15]. Pyrazinamide is usually administered as a two-month course during treatment of pulmonary tuberculosis, and hyperuricemia is reversible after withdrawal of the agent, therefore hyperuricemia due to pyrazinamide can be managed by observation and does not require withdrawal of the administration [16]. In the human kidney, uric acid is transported via URAT1 through the apical membrane of the proximal tubular cells, in exchange for organic anions, such as pyrazinoate, nicotinate, and lactate transported towards the tubular lumen. It has been reported that pyrazinamide reduces the renal secretion of uric acid via activation of the exchange transport of uric acid with pyrazinecarboxylic acid, which is a metabolite of pyrazinamide, through the uric acid transporter URAT1 $[17,18]$. Moreover, hOAT10-mediated ${ }^{14} \mathrm{C}$-urate uptake was elevated by an exchange with L-lactate, pyrazinoate, and nicotinate [19]. Ethambutol, another anti-tuberculous agent, also produces an increased serum concentration of uric acid in about $50 \%$ of patients, due to decreased renal excretion [20]. The mechanism of increased serum concentration of uric acid by ethambutol administration is not clear, though seems to differ from that of pyrazinamide and diuretics.

Nicotinic acid has been used to treat dyslipidemia. Nicotinic acid decreases the concentrations of both very-low-density lipoproteins (VLDL) and plasma triglyceride (TG), besides elevating HDL cholesterol. Elevated blood levels of uric acid have been noted with nicotinic acid therapy [21]. Uric acid raising effects of nicotinic acid may occur when the drug is given in therapeutic doses of $1,500 \mathrm{mg}$

Diuretics(loop and thiazide types)
b-blockers
Low dose aspirin
Pyrazinamide, Ethambutol
Nicotinic acid, Niacin
Lactic acid $^{\text {Cyclosporin(Neoral }}{ }^{\circledR}$, Sandimmune
Tacrolimus(Prograf $^{\circledR}$ )
Fructose, Xylitol, Theophylline
Levodopa(Sinemet $^{\circledR}$ )
Cytotoxic agents

\begin{tabular}{|c|}
\hline 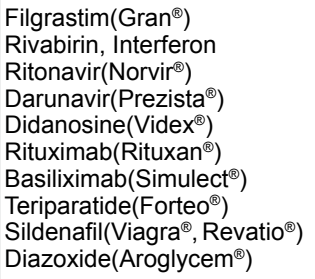 \\
\hline
\end{tabular}

Table 1: Drugs that raise serum uric acid. 
daily or doses of up to six grams. However, niceritorol, a niacin derivative, for 5 months' administration of $750 \mathrm{mg} /$ day seems to have no detrimental influence on serum uric acid concentration [22]. In addition to URAT1 mediated nicotinate exchanging for uric acid reabsorption, OAT 10 mediated uric acid uptake is also facilitated by exchange with nicotinate, suggesting the molecular evidence of nicotinate-induced hyperuricemia [19].

\section{Lactate}

Lactated Ringer's injection, has similar osmolarity to body fluids, is indicated as a source of water and electrolytes or as an alkalinizing agent. High dose lactate infusion (0.17-0.2 mol) leads to an increase in serum uric acid with a decrease in uric acid clearance $[23,24]$ However, lactate content in the high caloric solution (Flucaliq ${ }^{\mathrm{TM}}$ ) is $3.723 \mathrm{~g} / \mathrm{L}$, and high dose and long term administration of lactate is clinically rare, the effect of lactate infusion on the serum uric acid level may not be clinically important. During lactate is secreted through URAT1, uric acid is reabsorbed by exchange, causing an elevation of serum uric acid level. In addition to URAT1 mediated lactate exchanging for uric acid reabsorption, OAT 10 mediated uric acid uptake is also facilitated by exchange with lactate, suggesting the molecular evidence of lactateinduced hyperuricemia [19].

\section{Cyclosporine}

Cyclosporine $\mathrm{A}$ is used as a common immunosuppressant for management of organ transplantation and various autoimmune diseases. Cyclosporin A increases serum uric acid level by renal damage and/or decreased uric acid excretion. Although hyperuricemia is a well-known adverse effect of cyclosporine, tacrolimus also increases serum uric acid level [25]. On the contrary, azathioprine seems not to affect serum uric acid level. Recently it is revealed that cyclosporine A enhanced uric acid uptake through OAT10, providing molecular evidence for cyclosporine A-induced hyperuricemia [19] Cyclosporineinduced hyperuricemia is mitigated by concomitant administration of amlodipine or losartan [26,27].

\section{Testosterone}

Serum uric acid level of man is higher than that of woman, which is attributed to androgen-induced uric acid reabsorptive transport system in the kidney. According to a study using orchiectomized mice model, testosterone replacement enhanced mRNA and protein levels of sodium-coupled monocarboxylate transporter (SMCT1), while enhanced mRNA of URAT1, suggesting the induction of SMCT1 by testosterone is a candidate mechanism underlying hyperuricemia in males [28]. Testosterone replacement therapy against females with gender identity disorder increased serum uric acid level, and a positive correlation between increased levels of serum uric acid and serum creatinine. Thus it may be considered that testosterone-induced hyperuricemia is at least partially attributed to an increase in muscle mass, a major source of purine [29], although uric acid production is not estimated.

\section{Increased Uric Acid Overproduction}

Uric acid is produced by decomposition and catabolism of purine nucleotides, and external ingestion of purine body. It is endogenously produced by degradation of ATP or increased turnover rate of cell death. The diminution of ATP and the resulting elevation of AMP and IMP levels appear to trigger activation of purine nucleotide degradation. Certain drugs, such as fructose, xylitol, and theophylline can increase uric acid levels in the blood by accelerated purine nucleotide degradation, while certain cytotoxic agents increase uric acid production by an increased turnover rate of cell death.

\section{Fructose}

Fructose is widely used intravenously as a carbohydrate nutrient. Fructose infusion is indicated in patients requiring fluid replacement and caloric feeding. It is metabolized more rapidly than dextrose without requiring insulin and thus is used in diabetic patients. It is significantly metabolized to fructose-1-phosphate by fructokinase with an abrupt consumption of adenosine triphosphate (ATP) and phosphate, and increased activity of AMP deaminase suppressed by phosphate, consequently, degradation of adeninenucleotide is accelerated, hence increasing the synthesis of uric acid (Figure 3) [30]. Fructose also inhibits the excretion of uric acid, apparently by competing with uric acid for access to the transport protein GLUT 9 [31]. Fructose (1.0 g/ $\mathrm{kg}$ ) administration increased the plasma concentration of uric acid, together with an increase in the plasma concentration of oxypurines, supporting that an increase in the plasma concentration of uric acid is ascribable to increased purine degradation [32]. On the contrary, as $10 \%$ intravenous fructose $(0.5 \mathrm{~g}$. per $\mathrm{kg}$. body-weight per hour) did not appreciably change serum uric acid level, it is suggested that the hyperuricemic effect of fructose previously reported is dose-related and associated only with larger than physiological concentrations of fructose infused under experimental conditions [33]. Fructose should be infused at a speed below $0.5 \mathrm{~g} / \mathrm{kg} /$ hour to avoid a rise in uric acid level.

\section{Xylitol}

Xylitol has been suggested as a more advantageous calorie source for intravenous administration than glucose in certain clinical situation. Xylitol injection is indicated as the sugar substitutes for diabetics. However, xylitol increases uric acid levels particularly if higher doses are administered, as $0.25 \mathrm{~g} / \mathrm{kg} / \mathrm{hour}(1000 \mathrm{ml} 10 \%$ xylitol in approx. 8 hour) caused a distinct increase in the serum concentrations of uric acid., suggesting infusion of $100 \mathrm{~g}$ or more of

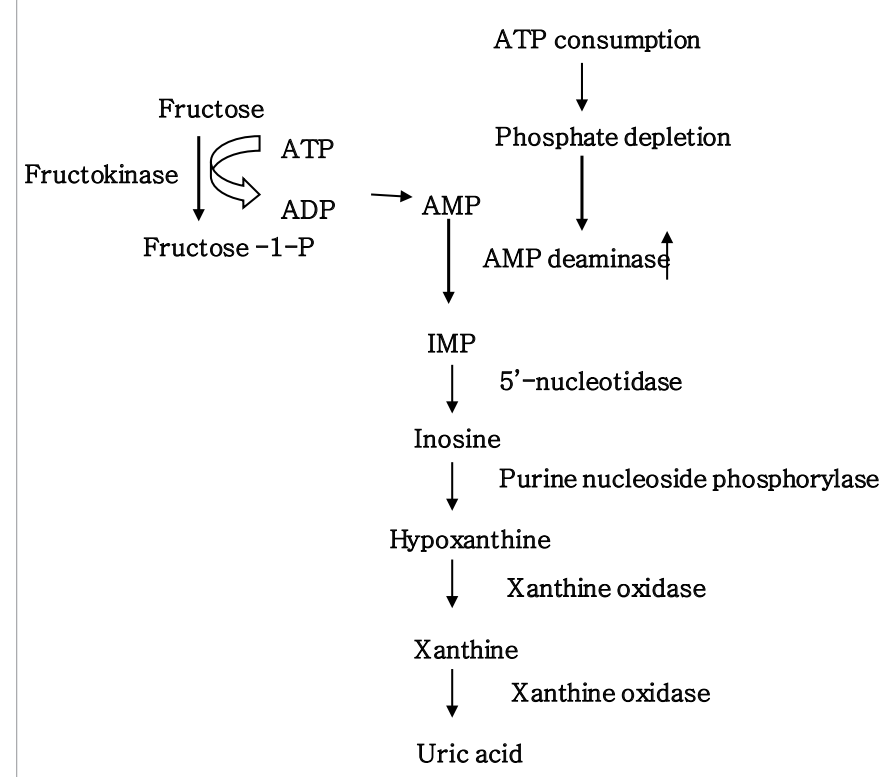

Figure 3: Adeninenucleotide degradation associated with fructose metabolism 
xylitol at a rate of $0.25 \mathrm{~g} / \mathrm{kg} /$ hour or faster is not safe [34]. Xylitol is first oxidized to $\mathrm{D}$-xylulose by the NAD-xylitol dehydrogenase, causing the $\mathrm{NADH} / \mathrm{NAD}$ ratio to increase. The next step is the phosphorylation of $\mathrm{D}$-xylulose to D-xylulose-5-phosphate by $\mathrm{D}$-xylulose-kinase, causing ATP and inorganic phosphate consumption. As a consequence, adeninenucleotide degradation is accelerated, resulting in buildup of serum uric acid level (Figure 4). Xylitol should be infused at a speed below $0.3 \mathrm{~g} / \mathrm{kg} /$ hour to avoid a rise in uric acid level.

\section{Theophylline}

Theophylline, a methylxanthine drug, is used for respiratory diseases such as bronchial asthma and chronic obstructive pulmonary disease (COPD) to prevent and treat symptoms including wheezing, shortness of breath, and chest tightness. The pharmacological actions of theophylline include bronchial smooth muscle dilatation, increased heart muscle contraction and renal blood flow, and anti-inflammatory effects. Serum uric acid concentration of the patients with asthma taking theophylline is higher than that not taking theophylline, and serum uric acid increases with serum theophylline concentrations [35]. Theophylline increased the plasma concentrations of purine bases (uric acid, hypoxanthine and xanthine) without a decreased urinary excretion of these purine bases in normal subjects. 1-methyl uric acid, a metabolite of theophylline, was not converted to uric acid, which suggested that theophylline-induced purine degradation seems to be a cause of the increased concentration of uric acid in plasma, although theophylline affected neither the concentration of nucleotides nor the activities of the enzymes related to purine metabolism (hypoxanthineguanine phosphoribosyl transferase, 5'-nucleotidase, adenosine deaminase and purine nucleoside phosphorylase [36].

\section{Cytotoxic agents}

Some cytotoxic agents, such as anthracyclines and doxorubicin derivatives cause raised levels of uric acid in the blood by renal damage and/or increased turnover rate of cell death. The extreme case of massive tumor cell lysis is named as tumor lysis syndrome, which release large amounts of nucleic acids into the systemic circulation. Catabolism of the nucleic acids to uric acid leads to hyperuricemia and marked increase in urinary uric acid excretion, as a consequence result in the precipitation of uric acid in the renal tubules, and acute kidney injury. Previously allopurinol is the only drug that lowers high levels of uric acid (a byproduct of metabolism) in the blood caused by some cancer treatments, and has been used for the prevention and treatment of tumor lysis syndrome, although, there are several limitations to its use. An alternative approach to allopurinol for lowering serum uric acid levels is to promote the degradation of uric acid by administration of uric acid oxidase. Rasburicase a recombinant version of uric acid oxidase has been available most recently. Rasburicase rapidly breaks down serum uric acid, and is effective in preventing and treating hyperuricemia and tumor lysis syndrome [37].

\section{Drugs that Lower Serum Uric Acid Concentration}

Drugs with hypouricemic properties, not primarily intended for the treatment of hyperuricemia include acetohexamide, azauridine, chlorprothixene, dicumarol, estrogens, fenofibrate, glyceryl guaiacolate, iopanoic acid, losartan, meglumine iodapamide, phenylbutazone, salicylates and other NSAIDs, sodium diatrizoate, trimetoprimsulfamethoxazole, and contrast media. Most known of which are estrogen, fenofibrate, and losartan. Decreased serum level of uric acid by drugs is mostly attributable to their uricosuric action, which is clinically not problematic and is considered to be rather preferable effect except for renal toxicity (Table 2).

\section{Increased Uric Acid Excretion}

\section{Estrogen}

Serum uric acid concentration of adult women is lower than in men of a similar age. Menopause is associated with higher serum uric acid levels and post-menopausal estrogen replacement decreases serum uric acid concentration [38]. The underlying mechanism is considered to be related to an increased renal clearance of uric acid in women, possibly due to their higher plasma estrogen levels [39,40]. Little has been known why estrogen increases renal uric acid excretion. However, recently it has been revealed that estradiol suppressed the protein levels of URAT1 and Glut9 [41].

\section{Antihypertensives (Sartans, calcium channel blockers)}

Effect of antihypertensives on uric acid metabolism differs from class to class. As mentioned above, diuretics raise serum uric acid, and $\beta$ blockers also raise serum uric acid level. Calcium antagonists increase uric acid clearance by increasing glomerular filtration. Effect of calcium

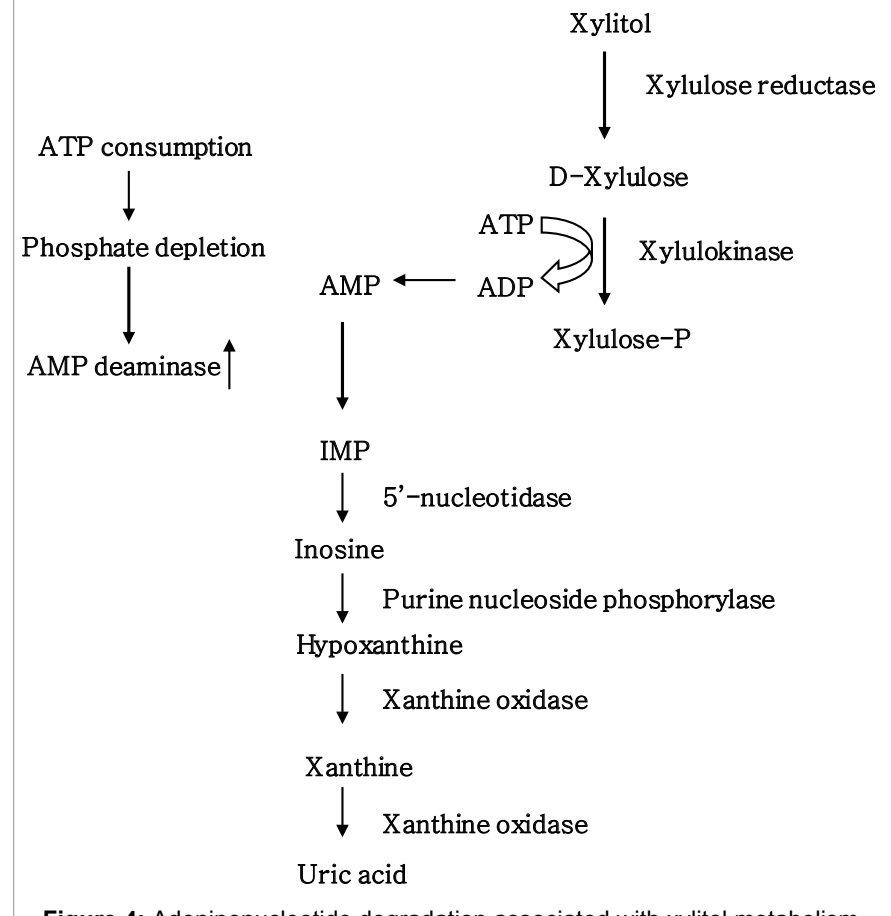

Figure 4: Adeninenucleotide degradation associated with xylitol metabolism.

\begin{tabular}{|c|c|}
\hline Salicylates(high doses) & Acetohexamide(Dimelin ${ }^{\circledR}$ ) \\
\hline Trimethoprim-Sulfamethoxazole & Azauridine \\
\hline Losartan(Neurotan ${ }^{\circledR}$ ) & Dicoumarol \\
\hline Nifedipine(Adalat ${ }^{\circledR}$ ) & Iopanoic acid \\
\hline Amlodipine(Norvasc ${ }^{\circledR}$ ) & Meglumine iodipamide \\
\hline Fenofibrate(Tricor $\left.{ }^{\circledR}\right)$ & Diatrizoate $\left(\right.$ Hypaque $\left.^{\circledR}\right)$ \\
\hline Atorvastatin(Lipitor $\left.{ }^{\circledR}\right)$ & Phenylbutazone \\
\hline Rosuvastatin(Crestor ${ }^{\circledR}$ ) & Calcitonin \\
\hline Chlorprothixene(Traquilan ${ }^{\circledR}$ ) & Kremezin \\
\hline Zotepine(Lodopin ${ }^{\circledR}$ ) & Sevelamer(Phosblock $\left.{ }^{\circledR}\right)$ \\
\hline Estrogens & Levotofisopam \\
\hline Glyceryl guaiacolate(Hustosil $\left.{ }^{\circledR}\right)$ & Tranilast(Rizaben ${ }^{\circledR}$ ) \\
\hline Vitamin C & o, p’-DDD(Opeprim ${ }^{\circledR}$ ) \\
\hline
\end{tabular}

Table 2: Drugs that lower serum uric acid. 
channel blockers and angiotensin converting enzyme (ACE)-inhibitors on serum uric acid level is controversial; some describe the uric acid lowering effect and others do not. Intravenous infusion of diltiazem has uricosuric and hypouricemic effects in rats, possibly due to an increase in glomerular filtration rate [42]. Neither serum uric acid nor clearance and fractional excretion of uric acid changed significantly during 10day treatment with nifedipine [43], while recent evidence suggested nifedipine has been found to reduce serum uric acid levels compared with a placebo in the A Coronary Disease Trial Investigating Outcome with Nifedipine GITS (ACTION) trial [44]. Furthermore, it has been suggested that amlodipine and cilnidipine might reduce serum uric acid level $[45,46]$. Captopril and enalapril increased uric acid excretion, and captopril significantly reduced serum uric acid in hypertensive patients with hyperuricemia [47], while it has been reported that ACEinhibitors have not been associated with lower serum uric levels $[48,49]$. Angiotensin II receptor blocker (ARB), losartan increased excretion of uric acid and decreased the serum uric acid level in both healthy and hypertensive subjects [50-52]. After $100 \mathrm{mg}$ administration of losartan, plasma concentrations of uric acid decreased by $8 \%$ and $16 \%$, at 1.5 and 2.5 hour, respectively. Urinary excretion of uric acid increased by 3.9fold and 2.6-fold, at 1 to 2 hour and at 2 to 3 hour, respectively, while the fractional clearance of uric acid was increased by 4.3 - and 3.2-fold at 1 to 2 hour and at 2 to 3 hour, respectively [53]. Therefore, losartan might be a useful therapeutic tool to control blood pressure and reduce serum uric acid levels in hypertensive patients with hyperuricemia and/ or gout. The uricosuric action of losartan is exerted by its inhibition of URAT1 expressed in the brush-border membrane of the renal proximal tubules $[54,55]$. Other ARBs have not been considered to affect serum uric acid level [56-58]. Thus, the effects of various ARBs on the disposition of uric acid might be different.

Data from Losartan Intervention For End point Reduction In Hypertension (LIFE) study suggest treatment-induced decrease in serum uric acid may contribute to the treatment benefit of a losartanbased versus atenolol-based therapy on the composite endpoint (death, myocardial infarction, or stroke) [59]. According to a large casecontrol study exploring the effect of antihypertensive drugs on the risk of incident gout attacks, calcium channel blockers and losartan are associated with a lower risk of incident gout among people with hypertension. By contrast, diuretics, $\beta$ blockers, angiotensin converting enzyme inhibitors, and non-losartan angiotensin II receptor blockers are associated with an increased risk of gout [60].

\section{Fenofibrate}

It has been shown that fenofibrate, a hypolipidemic fibric acid derivative decreases serum uric acid by $20 \%$ [61]. In hyperlipidemic patients, fenofibrate $(300 \mathrm{mg} /$ day) for 12 weeks decreased serum uric acid concentration by $36 \%$ and increased fractional uric acid clearance by $62 \%$ [62]. Three days' administration of fenofibrate $450 \mathrm{mg}$ increased fractional clearance of uric acid, compared to baseline value, while the plasma concentration decreased in normal subjects [63]. Mechanism by which fenofibrate decreases serum uric acid levels by increasing its urinary excretion is considered to be through the inhibition of URAT1 by fenofibric acid, major metabolite of fenofibrate [64]. An in vitro study using HEK 293 cells expressing URAT1 showed IC $_{50}$ of fenofibric acid is reported to be $35.68 \pm 3.94 \mu \mathrm{M}$ (benzbromarone, $0.13 \pm 0.01$ $\mathrm{mM}$ ) [64]

\section{Statins}

Statins are competitive inhibitors of the enzyme HMG-CoA reductase, and are used for the treatment of high LDL-cholesterol. Atorvastatin and rosuvastatin decrease serum uric acid levels, respectively, but pitavastatin dose not [65]. High dose atorvastatin (40 $\mathrm{mg}$ /day) significantly decreased serum uric acid levels although the underlying mechanisms remain speculative [66]. Rosvastatin (10 mg/ day) exhibits a similar uric acid-lowering effect [67].

\section{Decreased uric acid absorption}

Drugs that lower serum uric acid by decreased production have not been described except xanthine oxidase inhibitors, which are widely used for hyperuricemia/gout. Sevelamer, a nonabsorbed hydrogel that binds phosphorus and bile acids in the intestine, and used to treat hyperphosphatemia in CKD patients on hemodialysis, decreases serum uric acid concentration, possibly by adsorbing uric acid $[68,69]$. The reduction has not considered detrimental effect, rather a beneficial one.

\section{Drug that Raises or Lowers Serum Uric Acid According to its Doses (paradoxical effect)}

\section{Salicylate}

Salicylic acid and its derivatives are the most prescribed analgesic, antipyretic, and anti-inflammatory agents. Salicylates have a "paradoxical effect" on the handling of uric acid by the kidney. The action of salicylates on uric acid excretion depends on the dose of salicylates. At doses of less than $2.5 \mathrm{~g} /$ day, salicylates cause the retention of uric acid by blocking the tubular secretion of uric acid, while at dose of higher than $3 \mathrm{~g} /$ day, they cause increased urinary excretion of uric acid [70]. Mini-dose aspirin, even at a dosage of $75 \mathrm{mg} /$ day, caused a decrease in uric acid excretion and raised serum uric acid level [71]. It has been suggested that the "paradoxical effect" of salicylate can be explained by two modes of salicylate interaction with URAT1: (1) acting as an exchange substrate to facilitate uric acid reabsorption, and (2) acting as an inhibitor for uric acid reabsorption [72]. Low dose of salicylate interact with OAT1/OAT3, the uric acid secreters [73].

\section{Effects of various drugs on uric acid transporters are indicated in Figure 2}

Others: High-dose trimethoprim-sulfamethoxazole is associated with a reduction in serum uric acid concentration [74].

Chlorprothixene, a major tranquilizer shows strong uricosuric action and lowers serum uric acid, which may be used as an indicator of treatment compliance [75]. Zuclopenthixol, an antipsychotic drug of the thioxanthene class, is also a potent uricosuric agent, thus capable of producing persistent hypouricemia [76].

Tranilast, an anti-allergy drug originally developed in Japan, decreases serum uric acid level by increased urinary excretion. Tranilast can inhibit uric acid transport through both GLUT9 and URAT1 proteins, with an $\mathrm{IC}_{50}$ (approximately $16 \mathrm{mM}$ and $24 \mu \mathrm{M}$, respectively) consistent in each case with the level of exposure in humans resulting from doses that produce a uricosuric effect. This suggests that the uricosuric activity of tranilast is due to inhibition of these reabsorptive urate transporters in the kidney [77].

Levotofisopam is the S-entantiomer of the racemic mixture RStofisopam, a nonsedating agent used for the treatment of a variety of disorders associated with stress or autonomic instability. Tofisopam decreases serum uric acid level by increasing uric acid excretion (submitted). However, the target uric acid transporter of tofisopam remains to be clarified. 
It has been reported that administration of cilostazol $200 \mathrm{mg}$ for 12 weeks decreased serum uric acid, although the mechanism is not clear [78].

Hypouricemic effects of glyceryl guaiacolate, an expectorant and o,p'-DDD, an antineoplastic drug used to treat adrenocortical carcinoma by increased uric acid clearance have been reported $[79,80]$.

Choi et al. showed that people with a higher vitamin $\mathrm{C}$ intake have a lower risk of gout [81]. There is also a study in healthy volunteers that suggests that supplementation with $500 \mathrm{mg}$ /day of vitamin $\mathrm{C}$ for 2 months reduces serum uric acid levels [82]. Although the precise mechanism is unknown, it is considered that vitamin $\mathrm{C}$ increases the uric acid excretion [83-86]. However, a latest research revealed that modest dose of vitamin C (500 mg/day) for 8 weeks does not reduce uric acid level to a clinically significant degree in patients with gout [87].

\section{Conclusion}

To understand the effects of pharmacological agents on uric acid metabolism will help to avoid unexpected side effect of hyperuricemia and gout flare. In addition, availing hypouricemic property of some drugs, pleiotropic effects (antihypertensive+hypouricemic or antilipidemic+hypouricemic actions) and/or improvement of the medication compliance by avoiding multidrug therapy will be expected.

\section{References}

1. Higashino K, Moriwaki $Y$ (1996) Pharmacological agents affecting uric acid metabolism. Nihon Rinsho 54: 3364-3368.

2. Kahn AM (1988) Effect of diuretics on the renal handling of urate. Semin Nephrol 8: 305-314.

3. Hagos Y, Stein D, Ugele B, Burckhardt G, Bahn A (2007) Human renal organic anion transporter 4 operates as an asymmetric urate transporter. J Am Soc Nephrol 18: 430-439.

4. El-Sheikh AA, van den Heuvel JJ, Koenderink JB, Russel FG (2008) Effect of hypouricaemic and hyperuricaemic drugs on the renal urate efflux transporter, multidrug resistance protein 4. $\mathrm{Br} \mathrm{J}$ Pharmacol 155: 1066-1075.

5. Yamamoto T, Moriwaki Y, Takahashi S, Tsutsumi Z, Hada T (2001) Effect of furosemide on renal excretion of oxypurinol and purine bases. Metabolism 50: 241-245.

6. Hagos Y, Bahn A, Vormfelde SV, Brockmöller J, Burckhardt G (2007) Torasemide transport by organic anion transporters contributes to hyperuricemia. wJ Am Soc Nephrol 18: 3101-3109.

7. Jutabha P, Anzai N, Kitamura K, Taniguchi A, Kaneko S, et al. (2010) Human sodium phosphate transporter 4 (hNPT4/SLC17A3) as a common renal secretory pathway for drugs and urate. J Biol Chem 285: 35123-35132.

8. Hasegawa M, Kusuhara H, Adachi M, Schuetz JD, Takeuchi K, et al. (2007) Multidrug resistance-associated protein 4 is involved in the urinary excretion of hydrochlorothiazide and furosemide. J Am Soc Nephrol 18: 37-45.

9. Carlsen JE, Køber L, Torp-Pedersen C, Johansen P (1990) Relation between dose of bendrofluazide, antihypertensive effect, and adverse biochemical effects. BMJ 300: 975-978.

10. Reyes AJ (2003) Cardiovascular drugs and serum uric acid. Cardiovasc Drugs Ther 17: 397-414.

11. Takahashi $Y$, Nishida $Y$, Nakayama T, Asai S (2011) Adverse effect profile of trichlormethiazide: a retrospective observational study. Cardiovasc Diabetol 10: 45 .

12. Roos JC, Boer P, Peuker KH, Dorhout Mees EJ (1982) Changes in intrarenal uric acid handling during chronic spironolactone treatment in patients with essential hypertension. Nephron 32: 209-213.

13. Garcá Puig J, Miranda ME, Mateos F, Herrero E, Lavilla P, et al. (1991) Hydrochlorothiazide versus spironolactone: long-term metabolic modifications in patients with essential hypertension. J Clin Pharmacol 31: 455-461.
14. Cabrera SE, Edwards NC, Steeds RP, Townend JN, Ferro CJ (2013) Spironolactone increases serum uric acid levels in patients with chronic kidney disease. J Hum Hypertens.

15. Moriwaki Y, Yamamoto T, Takahashi S, Hada T, Higashino K (1990) Analysis of uric acid transport in renal tubules using benzbromarone and pyrazinamide. Int J ClinPharmacolTherToxicol 28: 84-88

16. Taki H, Ogawa K, Murakami T, Nikai T (2008) Epidemiological survey of hyperuricemia as an adverse reaction to antituberculous therapy with pyrazinamide. Kekkaku 83: 497-501.

17. de Vries A, Sperling O (1979) Inborn hypouricemia due to isolated renal tubular defect. Biomedicine 30: 75-80.

18. Enomoto A, Kimura H, Chairoungdua A, Shigeta $Y$, Jutabha $P$, et al. (2002) Molecular identification of a renal urate anion exchanger that regulates blood urate levels. Nature 417: 447-452.

19. Bahn A, Hagos $Y$, Reuter S, Balen D, Brzica $H$, et al. (2008) Identification of a new urate and high affinity nicotinate transporter, hOAT10 (SLC22A13). J Biol Chem 283: 16332-16341.

20. Narang RK, Agarwal MC, Raina AK, Singh SN, Bihari K, et al. (1983) Hyperuricaemia induced by ethambutol. $\mathrm{Br} \mathrm{J}$ Dis Chest 77: 403-406.

21. Kei A, Elisaf MS (2012) Nicotinic acid: clinical considerations. Expert Opin Drug Saf 11: 551-564.

22. Takahashi S, Yamamoto T, Moriwaki Y, Tsutsumi Z, Higashino K (1995) Increased concentrations of serum $L p(a)$ lipoprotein in patients with primary gout. Ann Rheum Dis 54: 90-93.

23. Burch RE, Kurke N (1968) The effect of lactate infusion on serum uric acid Proc Soc Exp Biol Med 127: 17-20.

24. Yamamoto T, Moriwaki Y, Takahashi S, Nasako Y, Higashino K (1993) Effect of lactate infusion on renal transport of purine bases and oxypurinol. Nephron 65: 73-76.

25. Kanbay M, Akcay A, Huddam B, Usluogullari CA, Arat Z, et al. (2005) Influence of cyclosporine and tacrolimus on serum uric acid levels in stable kidney transplant recipients. Transplant Proc 37: 3119-3120.

26. Chanard J, Toupance O, Lavaud S, Hurault de Ligny B, Bernaud C, et al. (2003) Amlodipine reduces cyclosporin-induced hyperuricaemia in hypertensive renal transplant recipients. Nephrol Dial Transplant 18: 2147-2153.

27. Kamper AL, Nielsen AH (2001) Uricosuric effect of losartan in patients with renal transplants. Transplantation 72: 671-674

28. Hosoyamada M, Takiue Y, Shibasaki T, Saito H (2010) The effect of testosterone upon the urate reabsorptive transport system in mouse kidney. Nucleosides Nucleotides Nucleic Acids 29: 574-579.

29. Kurahashi H, Watanabe M, Sugimoto M, Ariyoshi Y, Mahmood S, et al. (2013) Testosterone replacement elevates the serum uric acid levels in patients with female to male gender identity disorder. Endocr J.

30. Nakagawa T, Tuttle KR, Short RA, Johnson RJ (2005) Hypothesis: fructoseinduced hyperuricemia as a causal mechanism for the epidemic of the metabolic syndrome. Nat Clin Pract Nephrol 1: 80-86.

31. Vitart V, Rudan I, Hayward C, Gray NK, Floyd J, et al. (2008) SLC2A9 is a newly identified urate transporter influencing serum urate concentration, urate excretion and gout. Nat Genet 40: 437-442.

32. Yamamoto T, Moriwaki Y, Takahashi S, Yamakita J, Tsutsumi Z, et al. (1997) Effect of ethanol and fructose on plasma uridine and purine bases. Metabolism 46: 544-547.

33. Sahebjami $H$, Scalettar R (1971) Effects of fructose infusion on lactate and uric acid metabolism. Lancet 1: 366-369.

34. Korttila K, Mattila MA (1979) Increased serum concentrations of lactic, pyruvic and uric acid and bilibubin after postoperative xylitol infusion. Acta Anaesthesiol Scand 23: 273-277.

35. Morita $\mathrm{Y}$, Nishida $\mathrm{Y}$, Kamatani N, Miyamoto $T$ (1984) Theophylline increases serum uric acid levels. J Allergy Clin Immunol 74: 707-712.

36. Yamamoto T, Moriwaki Y, Suda M, Takahashi S, Hiroishi K, et al. (1991) Theophylline-induced increase in plasma uric acid--purine catabolism increased by theophylline. Int J Clin Pharmacol Ther Toxicol 29: 257-261. 
37. Bose P, Qubaiah O (2011) A review of tumour lysis syndrome with targeted therapies and the role of rasburicase. J Clin Pharm Ther 36: 299-326.

38. Hak AE, Choi HK (2008) Menopause, postmenopausal hormone use and serum uric acid levels in US women--the Third National Health and Nutrition Examination Survey. Arthritis Res Ther 10: R116.

39. Antón FM, García Puig J, Ramos T, González P, Ordás J (1986) Sex differences in uric acid metabolism in adults: evidence for a lack of influence of estradiol-17 beta (E2) on the renal handling of urate. Metabolism 35: 343-348.

40. Yahyaoui R, Esteva I, Haro-Mora JJ, Almaraz MC, Morcillo S, et al. (2008) Effect of long-term administration of cross-sex hormone therapy on serum and urinary uric acid in transsexual persons. J Clin Endocrinol Metab 93: 22302233.

41. Takiue Y, Hosoyamada M, Kimura M, Saito H (2011) The effect of female hormones upon urate transport systems in the mouse kidney. Nucleosides Nucleotides Nucleic Acids 30: 113-119.

42. Sugino $H$, Shimada $H(1996)$ Intravenous infusion of diltiazem causes uricosuria with concomitant hypouricemia in rats. Biol Pharm Bull 19: 627-629.

43. Tykarski A (1991) [Uric acid and arterial hypertension. III. Effect of nifedipine on serum uric acid level and its renal excretion in primary arterial hypertension] Pol Arch Med Wewn 86: 177-182.

44. Ruilope LM, Kirwan BA, de Brouwer S, Danchin N, Fox KA, et al. (2007) Uric acid and other renal function parameters in patients with stable angina pectoris participating in the ACTION trial: impact of nifedipine GITS (gastro-intestinal therapeutic system) and relation to outcome. J Hypertens 25: 1711-1718.

45. Mahmood IH (2008) Effects of captopril and amlodipine on serum uric acid in type 2 diabetic hypertensive patients. Rawal Med J 33: 52-55

46. Hamada T, Yamada K, Mizuta E, Watanabe A, Osaki T, et al. (2012) Effects of cilnidipine on serum uric acid level and urinary nitrogen monoxide excretion in patients with hypertension. Clin Exp Hypertens 34: 470-473.

47. Leary WP, Reyes AJ (1987) Angiotensin I converting enzyme inhibitors and the renal excretion of urate. Cardiovasc Drugs Ther 1: 29-38.

48. Alderman M, Aiyer KJ (2004) Uric acid: role in cardiovascular disease and effects of losartan. Curr Med Res Opin 20: 369-379.

49. Schmidt A, Gruber U, Böhmig G, Köller E, Mayer G (2001) The effect of ACE inhibitor and angiotensin II receptor antagonist therapy on serum uric acid levels and potassium homeostasis in hypertensive renal transplant recipients treated with CsA. Nephrol Dial Transplant 16: 1034-1037.

50. Nakashima M, Uematsu T, Kosuge K, Kanamaru M (1992) Pilot study of the uricosuric effect of DuP-753, a new angiotensin II receptor antagonist, in healthy subjects. Eur J Clin Pharmacol 42: 333-335.

51. Burnier M, Rutschmann B, Nussberger J, Versaggi J, Shahinfar S, et al. (1993) Salt-dependent renal effects of an angiotensin II antagonist in healthy subjects. Hypertension 22: 339-347.

52. Fauvel JP, Velon S, Berra N, Pozet N, Madonna O, et al. (1996) Effects of losartan on renal function in patients with essential hypertension. J Cardiovasc Pharmacol 28: 259-263.

53. Yamamoto T, Moriwaki Y, Takahashi S, Tsutsumi Z, Hada T (2000) Effect of losartan potassium, an angiotensin II receptor antagonist, on renal excretion of oxypurinol and purine bases. J Rheumatol 27: 2232-2236

54. Roch-Ramel F, Guisan B, Diezi J (1997) Effects of uricosuric and antiuricosuric agents on urate transport in human brush-border membrane vesicles. J Pharmacol Exp Ther 280: 839-845.

55. Hamada T, Ichida K, Hosoyamada M, Mizuta E, Yanagihara K, et al. (2008) Uricosuric action of losartan via the inhibition of urate transporter 1 (URAT 1) in hypertensive patients. Am J Hypertens 21: 1157-1162.

56. Sayin T, Döven O, Akyürek O, Dinçer I (2001) Neutral effect of valsartan on serum uric acid and renal function tests. J Hum Hypertens 15: 435-436.

57. Würzner G, Gerster JC, Chiolero A, Maillard M, Fallab-Stubi CL, et al (2001) Comparative effects of losartan and irbesartan on serum uric acid in hypertensive patients with hyperuricaemia and gout. J Hypertens 19: 18551860.

58. Rayner BL, Trinder YA, Baines D, Isaacs S, Opie LH (2006) Effect of losartan versus candesartan on uric acid, renal function, and fibrinogen in patients with hypertension and hyperuricemia associated with diuretics. Am J Hypertens 19 208-213.

59. Dahlöf B, Devereux R, de Faire U, Fyhrquist F, Hedner T, et al. (1997) The Losartan Intervention For Endpoint reduction (LIFE) in Hypertension study: rationale, design, and methods. The LIFE Study Group. Am J Hypertens 10: 705-713.

60. Choi HK, Soriano LC, Zhang Y, Rodríguez LA (2012) Antihypertensive drugs and risk of incident gout among patients with hypertension: population based case-control study. BMJ 344: d8190.

61. Bastow MD, Durrington PN, Ishola M (1988) Hypertriglyceridemia and hyperuricemia: effects of two fibric acid derivatives (bezafibrate and fenofibrate) in a double-blind, placebo-controlled trial. Metabolism 37: 217-220.

62. Noguchi Y, Tatsuno I, Suyama K, Shibata T, Yoshida T, et al. (2004) Effect of fenofibrate on uric acid metabolism in Japanese hyperlipidemic patients. $J$ Atheroscler Thromb 11: 335-340.

63. Yamamoto T, Moriwaki Y, Takahashi S, Tsutsumi Z, Hada T (2001) Effect of fenofibrate on plasma concentration and urinary excretion of purine bases and oxypurinol. J Rheumatol 28: 2294-2297.

64. Uetake D, Ohno I, Ichida K, Yamaguchi Y, Saikawa H, et al. (2010) Effect of fenofibrate on uric acid metabolism and urate transporter 1. Intern Med 49: $89-94$

65. Ogata N, Fujimori S, Oka Y, Kaneko K (2010) Effects of three strong statins (atorvastatin, pitavastatin, and rosuvastatin) on serum uric acid levels in dyslipidemic patients. Nucleosides Nucleotides Nucleic Acids 29: 321-324.

66. Milionis HJ, Kakafika AI, Tsouli SG, Athyros VG, Bairaktari ET, et al. (2004) Effects of statin treatment on uric acid homeostasis in patients with primary hyperlipidemia. Am Heart J 148: 635-640.

67. Moutzouri E, Liberopoulos EN, Florentin M, Liamis G, Elisaf MS (2013) Effects of statin monotherapy versus statin plus ezetimibe combination on serum uric acid levels. J CardiovascPharmacolTher 18: 13-18

68. Garg JP, Chasan-Taber S, Blair A, Plone M, Bommer J, et al. (2005) Effects of sevelamer and calcium-based phosphate binders on uric acid concentrations in patients undergoing hemodialysis: a randomized clinical trial. Arthritis Rheum 52: $290-295$

69. Ohno I, Yamaguchi Y, Saikawa H, Uetake D, Hikita M, et al. (2009) Sevelamer decreases serum uric acid concentration through adsorption of uric acid in maintenance hemodialysis patients. Intern Med 48: 415-420.

70. YU TF, GUTMAN AB (1959) Study of the paradoxical effects of salicylate in low, intermediate and high dosage on the renal mechanisms for excretion of urate in man. J Clin Invest 38: 1298-1315.

71. Caspi D, Lubart E, Graff E, Habot B, Yaron M, et al. (2000) The effect of minidose aspirin on renal function and uric acid handling in elderly patients. Arthritis Rheum 43: 103-108.

72. Ohtsu N, Anzai N, Fukutomi T, Kimura T, Sakurai H, et al. (2010) [Human renal urate transpoter URAT1 mediates the transport of salicylate]. Nihon Jinzo Gakkai Shi 52: 499-504.

73. Khamdang S, Takeda M, Noshiro R, Narikawa S, Enomoto A, et al. (2002) Interactions of human organic anion transporters and human organic cation transporters with nonsteroidal anti-inflammatory drugs. J Pharmacol Exp Ther 303: 534-539.

74. Chertow GM, Seifter JL, Christiansen CL, O'Donnell WJ (1996) Trimethoprimsulfamethoxazole and hypouricemia. Clin Nephrol 46: 193-198.

75. Shalev A, Hermesh H, Munitz H, Birger M (1989) Chlorprothixene-induced hypouricemia: a biologic indicator of drug compliance. J Clin Psychiatry 50: 424-427.

76. Bloch M, Gur E, Shalev AY (1992) Hypouricemic effect of zuclopenthixol: a potential marker of drug compliance. Psychopharmacology (Berl) 109: 377 378

77. Mandal, Asim, Emerling, Daniel, Serafini, et al. (2010) Tranilast inhibits urate transport mediated by URAT1 and GLUT9. Arthritis Rheum 62: 10-164.

78. Toyota T, Oikawa S, Abe R, Sano R, Suzuki N, et al. (2001) Effect of Cilostazo on lipid, uric Acid and glucose metabolism in patients with impaired glucose tolerance or type 2 diabetes mellitus. A double-blind, placebo-controlled study. Clin Drug Invest 21: 325-335. 
Citation: Moriwaki Y (2014) Effects on Uric Acid Metabolism of the Drugs except the Antihyperuricemics. J Bioequiv Availab 6: 010-017. doi:10.4172/ jbb.1000173

79. Ramsdell CM, Postlethwaite AE, Kelley WN (1974) Uricosuric effect of glyceryl guaiacolate. J Rheumatol 1: 114-116.

80. Zumoff B (1979) The hypouricemic effect of o,p'-DDD. Am J Med Sci 278: 145147.

81. Choi HK, Gao X, Curhan G (2009) Vitamin C intake and the risk of gout in men: a prospective study. Arch Intern Med 169: 502-507.

82. Huang HY, Appel LJ, Choi MJ, Gelber AC, Charleston J, et al. (2005) The effects of vitamin $C$ supplementation on serum concentrations of uric acid: results of a randomized controlled trial. Arthritis Rheum 52: 1843-1847.

83. Stein HB, Hasan A, Fox IH (1976) Ascorbic acid-induced uricosuria. A consequency of megavitamin therapy. Ann Intern Med 84: 385-388.
84. Sutton JL, Basu TK, Dickerson JW (1983) Effect of large doses of ascorbic acid in man on some nitrogenous components of urine. Hum Nutr Appl Nutr 37: $136-140$.

85. Berger L, Gerson CD, Yü TF (1977) The effect of ascorbic acid on uric acid excretion with a commentary on the renal handling of ascorbic acid. Am J Med 62: 71-76.

86. Mitch WE, Johnson MW, Kirshenbaum JM, Lopez RE (1981) Effect of large oral doses of ascorbic acid on uric acid excretion by normal subjects. Clin Pharmacol Ther 29: 318-321.

87. Stamp LK, O'Donnell JL, Frampton C, Drake JM, Zhang M, et al. (2013) Clinically insignificant effect of supplemental vitamin $C$ on serum urate in patients with gout: a pilot randomized controlled trial. Arthritis Rheum 65: 16361642. 